\title{
Molecular Weight Effects of Biscarbazole-Based Hole Transport Polymers on the Performance of Solid-State Dye-Sensitized Solar Cells
}

\author{
Minseon Kong ${ }^{1, \dagger}$, Kyeong Seok Kim ${ }^{1, \dagger}{ }^{+}$Nguyen Van Nga ${ }^{2,+} \mathbb{C}$, Yeonju Lee ${ }^{1}$, Yu Seong Jeon ${ }^{1}$, \\ Yunsung $\mathrm{Cho}^{3}{ }^{-1}$, Younghwan Kwon ${ }^{2, *}$ and Yoon Soo Han ${ }^{1, *}$ \\ 1 School of Advanced Materials and Chemical Engineering, Daegu Catholic University, \\ Gyeongbuk 38430, Korea; qewr1666@naver.com (M.K.); kks199@naver.com (K.S.K.); \\ kbg04213@naver.com (Y.L.); db5230@naver.com (Y.S.J.) \\ 2 Department of Chemical Engineering, Daegu University, Gyeongbuk 38435, Korea; vanngatdt@gmail.com \\ 3 School of Electronic and Electrical Engineering, Daegu Catholic University, Gyeongbuk 38430, Korea; \\ philos@cu.ac.kr \\ * Correspondence: y_kwon@daegu.ac.kr (Y.K.); yshancu@cu.ac.kr (Y.S.H.); Tel.: +82-53-850-6561 (Y.K.); \\ +82-53-850-2773 (Y.S.H.); Fax: +82-53-850-6569 (Y.K.); +82-53-359-6662 (Y.S.H.) \\ + These authors contributed equally to this work.
}

Received: 29 November 2020; Accepted: 14 December 2020; Published: 15 December 2020

\begin{abstract}
The leakage and volatilization of liquid electrolytes limit the commercialization of dye-sensitized solar cells (DSCs). As solid-state (ss) hole-transporting materials, free from leakage and volatilization, biscarbazole-based polymers with different molecular weights (PBCzA-H $(21,200 \mathrm{~g} / \mathrm{mol})$ and PBCzA-L $(2450 \mathrm{~g} / \mathrm{mol})$ ) were applied in combination with additives to produce ssDSCs. An ssDSC with PBCzA-H showed a better short-circuit current $\left(J_{s c}\right)$, open-circuit voltage $\left(V_{o c}\right)$, and fill factor $(F F)$ than a device with PBCzA-L, resulting in 38\% higher conversion efficiency. Compared to the PBCzA-L, the PBCzA-H with a higher molecular weight showed faster hole mobility and larger conductivity, leading to elevations in $J_{s c}$ via rapid hole transport, $V_{o c}$ via rapid hole extraction, and $F F$ via lowered series and elevated shunt resistances. Thus, it is believed that PBCzA-H is a useful candidate for replacing liquid electrolytes.
\end{abstract}

Keywords: solid-state dye-sensitized solar cell; biscarbazole; hole-transporting material; hole mobility

\section{Introduction}

Dye-sensitized solar cells (DSCs) have garnered attention for their real-world applications such as transparency, multicolor options, easy integration into architecture, and short energy payback time [1,2]. However, the potential problems caused by liquid electrolytes, such as leakage and liquid volatilization, limit their long-term performance and practicality. Solving leakage and volatilization requires replacing the liquid electrolytes in DSCs with a solid-state (ss) hole-transporting material (HTM), and thereby dye desorption can also be prevented. By applying an ssHTM, an ssDSC that is easier to encapsulate and series connect can be realized [3]. More specifically, by merely replacing conventional liquid electrolytes $\left(\mathrm{I}^{-} / \mathrm{I}_{3}{ }^{-}\right)$with ssHTMs while maintaining the basic structure of conventional DSCs with liquid electrolytes, a liquid-junction-based ssDSC with a configuration of glass/F-doped tin oxide (FTO)/mesoporous $\mathrm{TiO}_{2}$ :dye/ssHTM/platinized FTO/glass can be embodied.

Recent studies reported the photovoltaic properties of conventional liquid-junction-based ssDSCs [4-9]. A 5.4\% power conversion efficiency (PCE) was achieved when poly(3,4-ethylenedioxythiophene) was applied as an organic HTM with several additives in a liquid-junction-based ssDSC [4]. Inorganic HTMs, such as $\mathrm{CsSnI}_{2.95} \mathrm{~F}_{0.05}$ doped with $\mathrm{SnF}_{2}$ [5] and $\mathrm{Cs}_{2} \mathrm{SnI}_{6}$ with additives [6], were also 
applied, and liquid-junction-based ssDSCs showed PCEs of up to $10.2 \%$ and $7.8 \%$, respectively. Moreover, when metal complexes such as a blend of [Cu(tmby $\left.)_{2}(\mathrm{TFSI})_{2}\right]$ and $\left[\mathrm{Cu}(\mathrm{tmby})_{2}(\mathrm{TFSI})\right]$ (where "tmby" is 4,4',6,6'-tetramethyl-2,2'-bipyridine, and TFSI is bis(trifluoromethylsulfonyl)imide) [7], a blend of $\left[\mathrm{Cu}(\mathrm{II})(\mathrm{dmp})_{2}(\mathrm{TFSI})_{2}\right]$ and $[\mathrm{Cu}(\mathrm{I})(\mathrm{dmp})(\mathrm{TFSI})]$ (where dmp is 2,2'-dimethyl phenanthroline) [8], and a blend of [Co(bpyPY4)](OTf $)_{2}$ and [Co(bpyPY4)](OTf $)_{3}$ (where bpyPY4 is the hexadentate ligand 6,6'-bis(1,1-di(pyridin-2-yl)ethyl)-2,2'-bipyridine and OTf is the trifluoromethanesulfonate anion) [9] were doped with LiTFSI and 4-tert-butylpyridine (TBP) [or 4-(trifluoromethyl)pyridine], the best PCEs of liquid-junction-based ssDSCs were recorded as $11 \%, 8.2 \%$, and $5.68 \%$, respectively. These liquid-junction-based ssDSCs can be fabricated without a costly and complicate vacuum process (i.e., thermal deposition of metal electrode), compared to ssDSCs with a configuration of glass/FTO/mesoporous $\mathrm{TiO}_{2}$ :dye/ssHTM/metal electrode (Au or Ag).

Many carbazole derivatives have been applied as HTMs on organic electronics because of their excellent hole-transporting capabilities and chemical stability [3,10-13]. Carbazole moiety represents a good electron-donating nature due to the nitrogen atoms' presence, which accounts for its derivatives' superior hole mobilities. Moreover, a wide variety of functional groups can be introduced to it due to its versatile reactive sites, leading to the facile tuning of electro-optical properties and film-forming capabilities.

In this study, biscarbazole-based hole-transporting polymers with different molecular weights were synthesized using procedures presented in the literature [14-17], and their molecular orbital energy levels, such as ionization potential, electron affinity, and bandgap energy, were measured. Moreover, we fabricated liquid-junction-based ssDSCs with the biscarbazole-based polymers and investigated the effects of molecular weight on the photovoltaic performance of ssDSCs. A thorough search of the relevant literature yielded no reports of liquid-junction-based ssDSCs with biscarbazole-type polymeric HTMs.

\section{Materials and Methods}

\subsection{Materials}

The following chemicals were purchased from Sigma-Aldrich (St. Louis, MO, USA): $N$-carbazole ( $\geq 95 \%), N$-2-ethylhexyl bromide $(97 \%)$, iron (III) chloride (97\%), 4-bromophenol (99\%), potassium carbonate ( $\geq 98 \%$ ), potassium phosphate ( $\geq 98 \%$ ), copper (II) iodide $(98 \%)$, trans-1,2-cyclohexanediamine $(99 \%)$, sodium hydride (60\% dispersion in mineral oil), sodium tert-butoxide (NaO-t-Bu, $97 \%)$, tri-tert-butylphosphine $\left(\mathrm{P}(t-\mathrm{Bu})_{3}, 90 \%\right)$, tris(dibenaylidene-acetone)dipalladium $(0)\left(\mathrm{Pd}_{2}\left(\mathrm{dba}_{3}\right)\right.$, and $\mathrm{N}$-bromosuccinimide (99\%). Other chemicals for synthesizing polymeric HTMs were reagent grade and used without further purification.

Commercial FTO (sheet resistance $\sim 7 \Omega$ /square) glass (TCO22-7), $\mathrm{TiO}_{2}$ pastes for the photoelectrode (Ti-nanoxide T/SP) and scattering layer (Ti-nanoxide R/SP), N719 dye (Ruthenizer 535-bisTBA), and hot-melt adhesive (Metlonix 1170-25, DuPont Surlyn) were all purchased from Solaronix (Aubonne, Switzerland). $\mathrm{TiCl}_{4}$, LiTFSI, TBP, and 1-methyl-3-propylimidazolium iodide (MPII) were purchased from Sigma-Aldrich (St. Louis, MO, USA). We selected platinum paste (PT-1, acquired from Dyesol-Timo JV, Seoul, Korea) as the Pt counter-electrode source. An indium tin

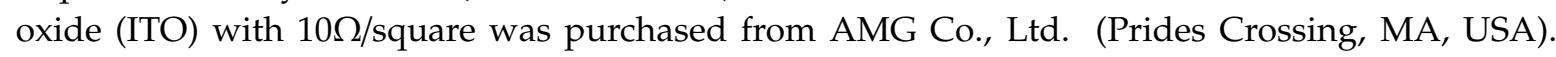
A poly(3,4-ethylenedioxythiophene)/poly(styrenesulfonate) (PEDOT:PSS, Baytron P VP Al 4083) was received from H.C. Starck GmbH. All the chemicals for DSC fabrication were used without further purification.

\subsection{Synthesis of poly\{bis-[6-N-(2-Ethylhexyl)-carbazole-3-yl]-alt-aniline\} (PBCzA)}

The biscarbazole-based hole-transporting polymers were synthesized using methods presented in the literature [14-17]. Bis[6-bromo-N-(2-ethylhexyl)-carbazole-3-yl] as a monomer was firstly synthesized $[14,15]$ and then copolymerized with aniline to give PBCzA [16,17]. Detailed procedures, 
reaction schemes (Schemes S1 and S2), and characterization results (Figures S1-S6) are provided in the Supplementary Materials section.

\subsection{Fabrication of ssDSCs}

Working electrodes with a layer structure of glass/FTO/TiO $: \mathrm{N} 719$ dye and counter electrodes with a layer structure of platinized FTO/glass were prepared using the same procedures presented in an earlier work by this study's researchers [18]. The counter electrodes were placed on the working electrodes and sealed with a $25 \mu \mathrm{m}$ thick sealing material by annealing for $10 \mathrm{~min}$ at $120^{\circ} \mathrm{C}$.

Synthesized PBCzA (50 mg) was dissolved in $1 \mathrm{~mL}$ of chloroform to replace the conventional liquid electrolyte $\left(\mathrm{I}^{-} / \mathrm{I}_{3}{ }^{-}\right)$with an ssHTM. An additive solution was prepared separately by dissolving LiTFSI (0.066 M, $19 \mathrm{mg})$, TBP (0.2 M, $27 \mathrm{mg})$, and MPII (1.0 M, $252 \mathrm{mg})$ in $1 \mathrm{~mL}$ of chloroform [4]. The polymer and additive solutions were mixed with a 3:1 volume ratio before application to the ss hole-transporting layers of the ssDSCs. The resulting mixed solution was then injected into the sealed cells through a predrilled hole on the counter electrodes, and the cells were dried in a vacuum oven for $60 \mathrm{~min}$ at $50{ }^{\circ} \mathrm{C}$. This injection and drying process was repeated four times to fill the space between the mesoporous $\mathrm{TiO}_{2}$ layer and the platinized FTO layer, thereby fabricating liquid-junction-based ssDSCs with a $25 \mathrm{~mm}^{2}$ active area.

\subsection{Fabrication of Hole-Only Devices}

Additive-free hole-only devices were fabricated with a diode configuration of ITO/PEDOT/PSS $(30 \mathrm{~nm}) / \mathrm{PBCzA}(100 \mathrm{~nm}) / \mathrm{Au}(70 \mathrm{~nm})$ to estimate the hole mobility of the synthesized PBCzA with molecular weight. The same procedures presented in earlier work [19] were utilized to prepare the hole-only devices, and detailed fabrication conditions are provided in the Supplementary Materials.

We also fabricated additive-containing hole-only devices with the layer structure of glass/platinized $\mathrm{FTO} / \mathrm{TiO}_{2}: \mathrm{N} 719$ dye/HTM with additives/platinized FTO/glass. Both mesoporous and scattering $\mathrm{TiO}_{2}$ layers were formed on a counter electrode, and the $\mathrm{TiO}_{2}$ was sensitized with $\mathrm{N} 719$ dyes. This electrode (glass/platinized $\mathrm{FTO} / \mathrm{TiO}_{2}: \mathrm{N} 719$ dye) was sealed with another counter electrode (platinized FTO/glass) using a $25 \mu \mathrm{m}$ thick sealing material. The mixed polymer and additive solutions were injected into the sealed cell through a predrilled hole on the counter electrode, and the cell was dried in a vacuum oven for $30 \mathrm{~min}$ at $50{ }^{\circ} \mathrm{C}$. The injection and drying process was repeated four times to produce additive-containing hole-only devices.

\subsection{Measurements}

The ${ }^{1} \mathrm{H}$ and ${ }^{13} \mathrm{C}$ NMR spectra were obtained using a Varian Unity Plus 300 spectrometer (Varian Inc, Palo Alto, CA, USA), and chemical shifts were recorded in ppm. UV-visible absorption spectra were recorded on a UV-2100 spectrophotometer (Shimadzu Corporation, Kyoto, Japan), and the photoluminescence (PL) spectra were measured on a RF-5301PC fluorometer (Shimadzu Corporation, Kyoto, Japan). The highest occupied molecular orbital (HOMO) energy level was measured using photoelectron spectroscopy (AC-2, Hitachi High-Tech Corporation, Tokyo, Japan). Molecular weight and molecular weight distributions of polymers were obtained using Waters gel permeation chromatography (515 HPLC pump \& 410 differential refractometer, Waters Corp., Milford, MA, USA) equipped with Styragel HR 4E, Styragel HR 3E, and Styragel HR 1E columns while using tetrahydrofuran (THF) as an eluent against polystyrene standards at $40^{\circ} \mathrm{C}$.

The cross-sectional morphology of the completed ssDSCs was visualized via field-emission scanning electron microscopy (FE-SEM; S-4800, Hitachi High-Technology, Tokyo, Japan). The photocurrent-voltage measurement and electrochemical impedance spectroscopic (EIS) analysis were performed using a CompactStat potentiostat (Ivium Technologies BV, Eindhoven, The Netherlands). A PEC-L01 solar simulator system equipped with a $150 \mathrm{~W}$ xenon arc lamp (Peccell Technologies, Inc., Yokohama, Japan) was used as light source. The light intensity was adjusted to 1 sun $\left(100 \mathrm{~mW} / \mathrm{cm}^{2}\right)$ with a silicon photodiode (model PEC-SI01, Peccell Technologies, Inc., 
Yokohama, Japan). The dye-adsorbed $\mathrm{TiO}_{2}$ films' active areas were estimated using a digital microscope camera (SZ61, OLYMPUS Corporation, Tokyo, Japan) with image analysis software. All measurements were carried out under ambient conditions at room temperature.

\section{Results and Discussion}

\subsection{Photophysical and Electrochemical Properties of PBCzAs}

Synthesized PBCzA polymer was split into high-molecular-weight(PBCzA-H) and low-molecular-weight (PBCzA-L) fractions via a repetitive reprecipitation procedure. The weight-average molecular weight and molecular weight distribution of polymers were measured at 21,200 g/mol and 2.6 for PBCzA-H and $2450 \mathrm{~g} / \mathrm{mol}$ and 1.3 for PBCzA-L, respectively (Figure S7). The UV-Vis absorption and PL spectra of PBCzA-H and PBCzA-L in chlorobenzene solutions and films are presented in Figure S8a,b of the Supplementary Materials, respectively. The optical bandgap energy (Eg) of PBCzAs was calculated from the intersection points between the UV-Vis absorption and PL spectra of film-state PBCzAs. In both PBCzA-H and PBCzA-L, the intersection point was observed at $437 \mathrm{~nm}$, corresponding to an $\mathrm{Eg}$ of $2.84 \mathrm{eV}$. As shown in Figure S9, the HOMO energy levels of PBCz-A and PBCz-L were approximately equal within measurement error. We selected $-5.11 \mathrm{eV}$ as the $\mathrm{HOMO}$ energy of the polymers. Thus, the lowest unoccupied molecular orbital (LUMO) energy levels of PBCzA-H and PBCzA-L were calculated as $-2.27 \mathrm{eV}$. These Eg, HOMO, and LUMO energy levels suggest that the synthesized PBCzAs have potential as a HTM (Figure 1). Molecular weight, molecular weight distribution, and photophysical and electrochemical properties of PBCzAs are summarized in Table 1.

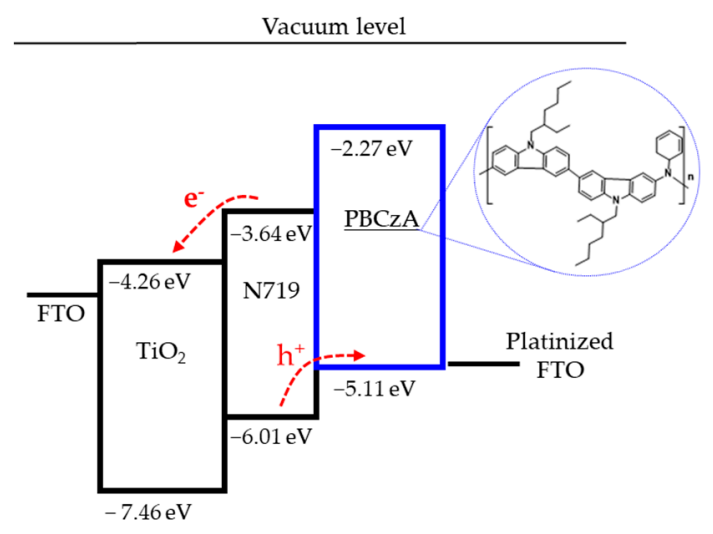

Figure 1. Schematic energy band diagram of solid-state dye-sensitized solar cells (ssDSC) with hole-transporting PCBzA. Inset shows the chemical structure of PBCzA.

Table 1. Summary of molecular weight, photophysical and electrochemical properties of PBCzAs.

\begin{tabular}{cccccccc}
\hline HTM & $\begin{array}{c}\text { Mw } \\
(\mathbf{g} / \mathbf{m o l})\end{array}$ & PDI & $\begin{array}{c}\lambda_{\max , \mathbf{U V}} \\
(\mathbf{n m})\end{array}$ & $\begin{array}{c}\lambda_{\max , \mathbf{P L}} \\
(\mathbf{n m})\end{array}$ & $\begin{array}{c}\text { Eg } \\
(\mathbf{e V})\end{array}$ & $\begin{array}{c}\text { HOMO } \\
(\mathbf{e V})\end{array}$ & $\begin{array}{c}\text { LUMO } \\
(\mathbf{e V})\end{array}$ \\
\hline PBCzA-H & 21,200 & 2.6 & 302 & 450 & 2.84 & -5.11 & -2.27 \\
PBCzA-L & 2450 & 1.3 & 302 & 448 & 2.84 & -5.11 & -2.27 \\
\hline
\end{tabular}

\subsection{Photovoltaic Performance of ssDSCs with PBCzA-H and PBCzA-L}

We fabricated ssDSCs with PBCzA-H (21,200 g/mol) and PBCZA-L (2450 g/mol) as HTMs and measured their photovoltaic properties to investigate the impact of molecular weight on the device performance. Figure 2 shows the variations in the averaged photovoltaic parameters with the molecular weight of PBCzA. The detailed device performance is compared in Table S1 in the Supplementary Materials. Higher PCEs were achieved in the liquid-junction-based ssDSCs with PBCzA-H compared to the PCEs of devices with PBCzA-L. When the PBCzA-L was applied as a hole-transporting layer combined with additives (LiTFSI, TBP, and MPII), the ssDSCs showed a PCE of $2.51 \pm 0.17 \%$. In contrast, 
an increase in all parameters (i.e., short-circuit current $\left(J_{s c}\right)$, open-circuit voltage $\left(V_{o c}\right)$ and fill factor $(F F)$ ) resulted in a higher PCE of $3.15 \pm 0.43 \%$ for the device with PBCzA-H and the additives.
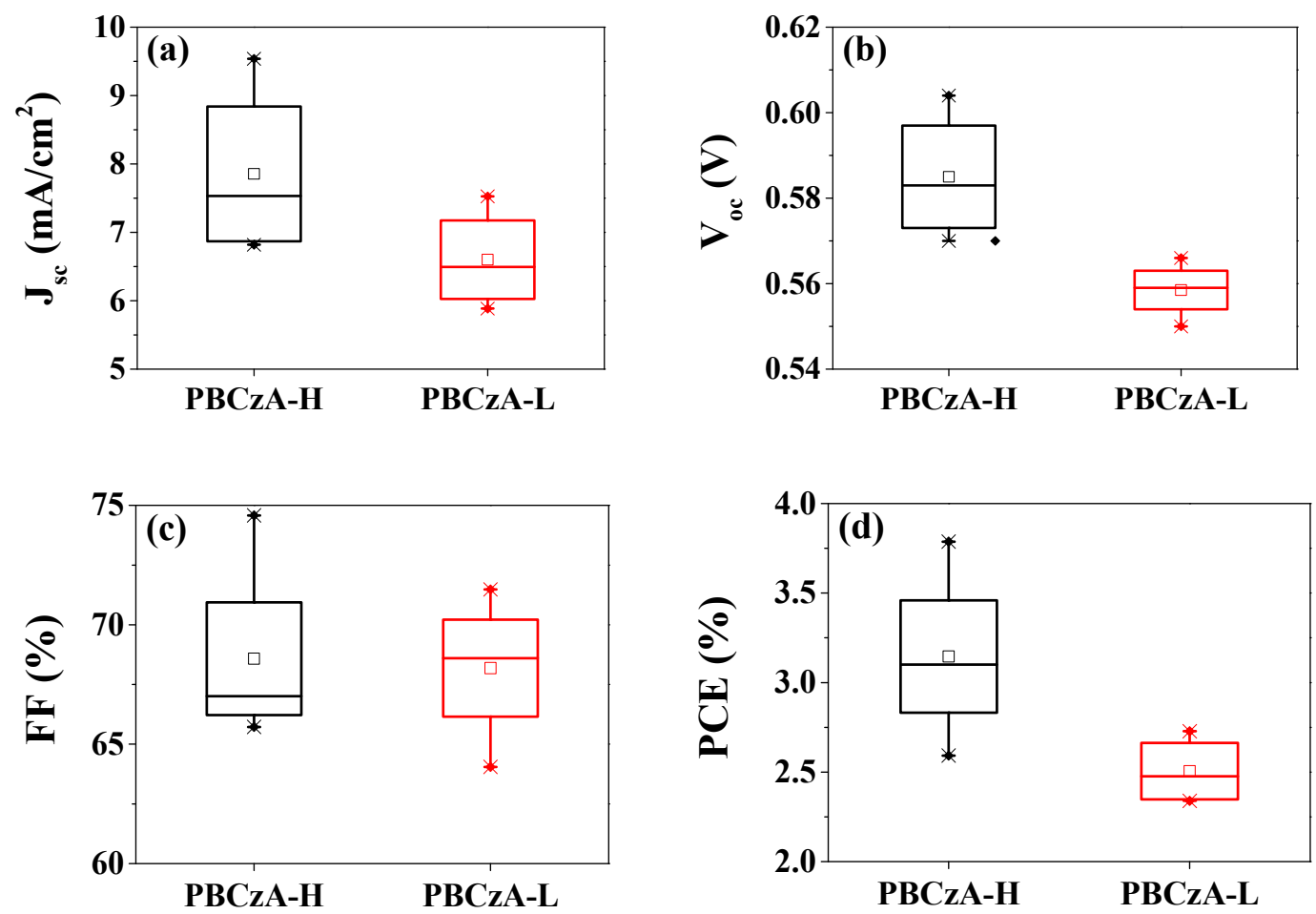

Figure 2. Comparison of photovoltaic parameters with molecular weights of PBCzA: (a) $J_{s c},(\mathbf{b}) V_{o c}$, (c) FF, and (d) PCE of the ssDSCs measured under AM $1.5\left(100 \mathrm{~mW} / \mathrm{cm}^{2}\right)$ illumination. Symbols $\mathrm{x},-, \square$ stand for minimum or maximum, $1 \%$ or $99 \%$ and averaged values, respectively. The bottom and upper sides of the square indicate lower and upper quartiles, respectively.

Revealing the superior PCE's origins is essential, necessitating a focus on ssDSCs that show the highest PCEs among the four cells. Here, we denote an ssDSC (3.79\% of PCE) with PBCzA-H by ssDSC-H and an ssDSC ( $2.73 \%$ of PCE) with PBCzA-L by ssDSC-L, respectively. Figure 3 shows the current density $(J)$ and voltage $(V)$ curves of the ssDSC-H and ssDSC-L, and the device performance is compared in Table 2. The superior PCE in the ssDSC-H was attributed to better performance in $J_{s c}, V_{o c}$, and FF compared to ssDSC-L. We examined the origins of the enhancement in all the photovoltaic parameters, and the analysis results are described in detail in the following sections.

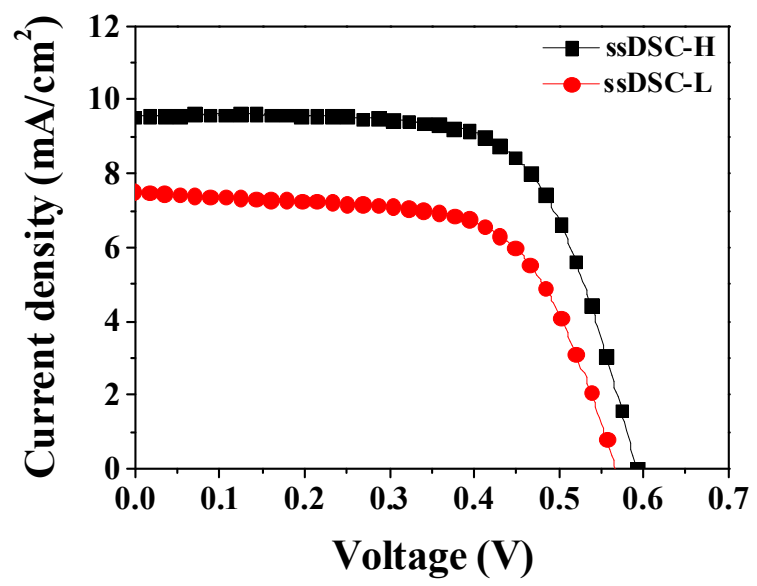

Figure 3. $J-V$ characteristics of the ssDSC-H and the ssDSC-L. 
Table 2. Performance comparison of ssDSCs showing the highest PCEs.

\begin{tabular}{cccccccc}
\hline Devices & HTM & $\begin{array}{c}J_{\text {sc }} \\
\left(\mathbf{m A} / \mathbf{c m}^{\mathbf{2}}\right)\end{array}$ & $\begin{array}{c}V_{\text {oc }} \\
(\mathbf{m V})\end{array}$ & $\begin{array}{c}\boldsymbol{F F} \\
\mathbf{( \% )}\end{array}$ & $\begin{array}{c}\boldsymbol{P C E} \\
\mathbf{( \% )}\end{array}$ & $\begin{array}{c}\boldsymbol{R}_{\boldsymbol{s e}} \\
\left(\boldsymbol{\Omega} \mathbf{c m}^{\mathbf{2}}\right)\end{array}$ & $\begin{array}{c}\boldsymbol{R}_{\text {sh }} \\
\left(\boldsymbol{\Omega} \mathbf{c m}^{\mathbf{2}}\right)\end{array}$ \\
\hline ssDSC-H & PBCzA-H & 9.54 & 0.590 & 67.30 & 3.79 & 11.0 & 1238.4 \\
ssDSC-L & PBCzA-L & 7.53 & 0.566 & 64.05 & 2.73 & 13.3 & 1100.1 \\
\hline
\end{tabular}

\subsection{Effects of the Molecular Weight on $J_{s c}$}

By utilizing the PBCzA-H as a HTM, the ssDSC-H device's $J_{s c}$ value increased by $9.54 \mathrm{~mA} / \mathrm{cm}^{2}$ compared to ssDSC-L's $7.53 \mathrm{~mA} / \mathrm{cm}^{2}$, corresponding to a contribution of approximately $72 \%$ to the PCE's enhancement. The diffusion length $\left(L_{d}\right)$ is the average distance that the excess carriers can cover before they recombine and can be expressed in the following equation:

$$
L_{d}=\sqrt{2 \frac{k_{B} T}{q} \mu \tau}
$$

where $\mu, k_{B}, T, \tau$, and $q$ are the carrier mobility, the Boltzmann constant, the absolute temperature, the carrier lifetime, and the electron charge, respectively [20-22].

In an organic semiconductor, the diffusion length of electrons and holes is about $100 \mathrm{~nm}$, whereas for a single crystalline silicon solar cell, it is typically $100-300 \mu \mathrm{m}$ [22-24]. Thus, the diffusion length $\left(L_{d}\right)$, which is proportional to the square root of the carrier mobility $(\mu)$, is one of the largest factors affecting $J_{s c}$ values in ssDSCs. Carrier mobility is particularly critical in liquid-junction-based ssDSCs because the distance between the top of the mesoporous $\mathrm{TiO}_{2}$ layer and the Pt counter electrode is about $7.1 \mu \mathrm{m}$ (Figure 4a). It is well known that polymers poorly penetrate the mesopores of $\mathrm{TiO}_{2}$ photoelectrodes, which arises from mismatches between the polymer sizes and the mesopore sizes [4]. Figure $4 \mathrm{~b}$ shows an EDS mapping image of carbon in a decaped ssDSC with $\mathrm{N719}$ dye-free $\mathrm{TiO}_{2}$ and additive-free PBCzA-H layers. As seen in Figure $4 b$, the polymeric HTM (PBCzA-H) nonuniformly penetrated the mesopores of $\mathrm{TiO}_{2}$ photoelectrodes. In other words, the pore filling of the $\mathrm{TiO}_{2}$ layer was not complete. EDS mapping images of other elements such as N, Ti, and O are displayed in Figure S10 of the Supplementary Materials. Incomplete pore filling still remained in the case of lower-molecular-weight PBCzA-L, as shown in Figure S11b of the Supplementary Materials.
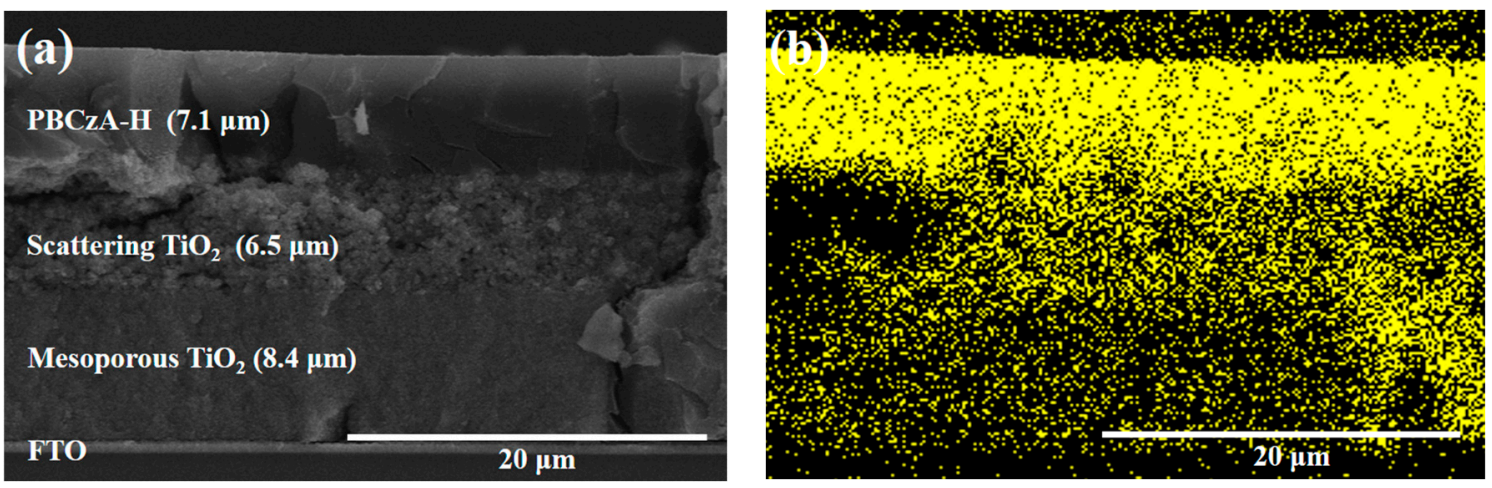

Figure 4. Cross-sectional SEM image (a) and EDS mapping (b) showing the distribution of carbon in a decapped ssDSC with PBCzA-H (without additives).

The additive-free hole-only devices were fabricated using the PBCzA-H and PBCzA-L before their dark current-voltage characteristics were measured to estimate the effects of molecular weight on the hole mobility. Space-charge-limited current (SCLC) measurements have been used to evaluate charge mobility under steady-state currents in organic layers $[19,25,26]$. Using the SCLC method, we could 
evaluate the hole mobility of the HTMs (PBCzA-H and PBCzA-L) with different molecular weights. The current density $(J)$ in the SCLC model is given in Equation (2):

$$
J=\frac{9}{8} \varepsilon_{r} \varepsilon_{0} \mu_{h 0} \frac{V^{2}}{L^{3}} \exp \left(0.89 \sqrt{\frac{V}{E_{0} L}}\right)
$$

where $\varepsilon_{r}$ is the dielectric constant (assumed to be three, a typical value for conjugated polymers) of the polymer, $\varepsilon_{0}$ is the permittivity of free space, $\mu_{h 0}$ is the zero-field hole mobility, $\mathrm{L}$ is the film thickness, $\mathrm{E}_{0}$ is the characteristic field, and $\mathrm{V}$ is equal to $V_{a p p l}-\left(V_{r}+V_{b i}\right)\left(V_{a p p l}\right.$ : the applied voltage to the device, $V_{r}$ : the voltage drop due to series resistance across the electrodes, and $V_{b i}$ : the built-in voltage).

Figure 5 a shows the experimental dark current densities of additive-free hole-only devices with PBCzA-H and PBCzA-L films. The devices' hole mobility was calculated from Equation (2) using the $J-V$ data of the hole-only devices with a configuration of ITO/PEDOT/PSS ( $30 \mathrm{~nm}$ )/PBCzA $(100 \mathrm{~nm}) / \mathrm{Au}(70 \mathrm{~nm})$. This configuration can obstruct the electron injection from the Au electrode due to the large mismatch between the PBCzA's LUMO energy level $(2.27 \mathrm{eV})$ and the Au cathode's work function $\left(5.10 \mathrm{eV}\right.$ ). In the logarithm of $\mathrm{JL}^{3} / \mathrm{V}^{2}$ versus the square root of $\mathrm{V} / \mathrm{L}$ (as shown in Figure $5 \mathrm{~b}^{\prime} \mathrm{s}$ graph), this line's intercept gives the hole mobility.
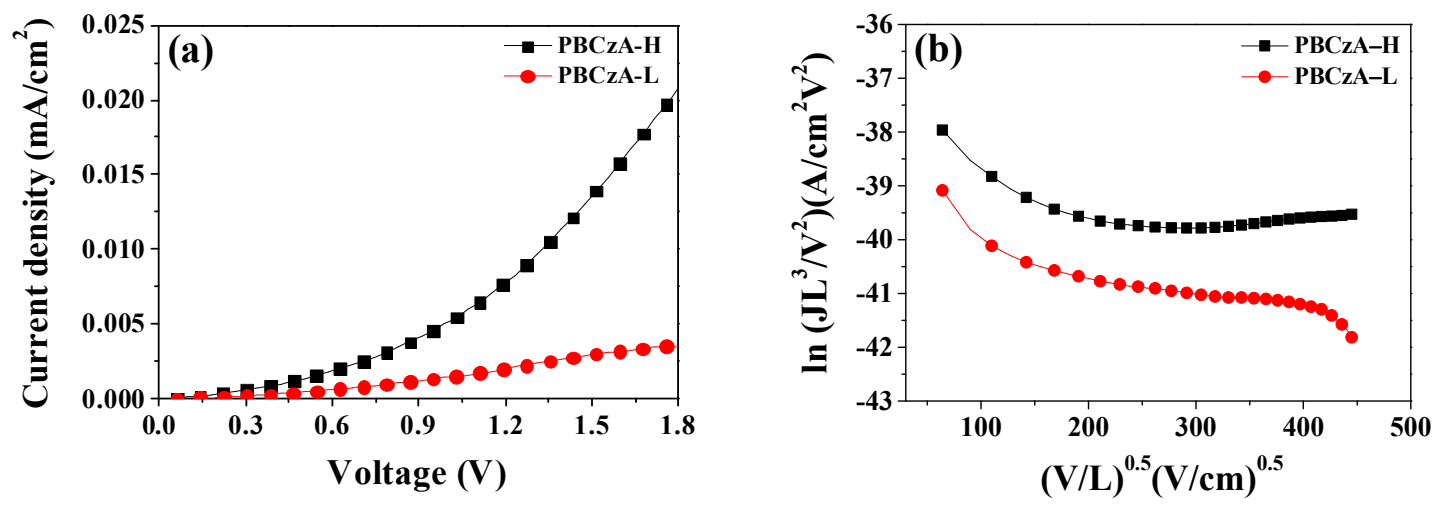

Figure 5. $J-V$ characteristics of the hole-only devices measured in the dark (a) and $\ln \left(\mathrm{JL}^{3} / \mathrm{V}^{2}\right)$ versus $(\mathrm{V} / \mathrm{L})^{0.5}$ curves $(\mathbf{b})$ based on the space-charge-limited current (SCLC) equation.

The averaged hole mobility of six hole-only devices with PBCzA-L was calculated as $1.50 \pm 0.50 \times 10^{-5} \mathrm{~cm}^{2} / \mathrm{Vs}$, whereas the device with PBCzA-H had a value as high as $4.33 \pm 1.25 \times 10^{-5} \mathrm{~cm}^{2} /$ Vs (Figure 6). The hole mobility of the additive-free hole-only device with PBCzA-H was about 290\% higher than that of the device with PBCzA-L. The increased hole mobility of the device with PBCzA-H was attributed to more effective charge transport through the PBCzA backbone because a longer chain length in PBCzA-H can provide a more effective intramolecular charge transport (i.e., it can decrease the intermolecular charge transport's frequency) $[27,28]$. The additive-containing hole-only devices were also fabricated, and their dark current-voltage characteristics were measured to confirm the molecular weight's effects. As shown in Figure 7, the additive-containing device's dark currents with PBCzA-H are higher than those with PBCzA-L, which are consistent with the additive-free hole-only devices' results. This result indicates that the PBCzA-H's hole mobility is higher than that of the PBCzA-L. 


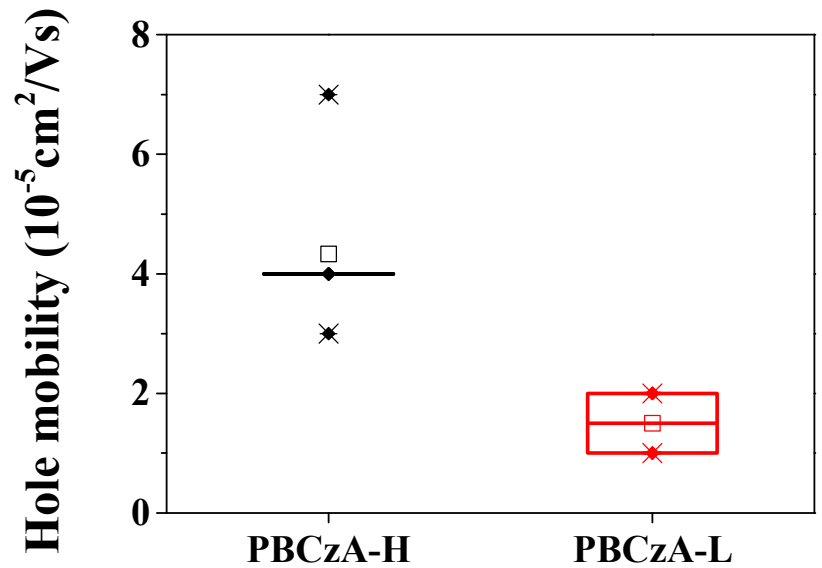

Figure 6. Hole mobilities of PBCzAs calculated using $J-V$ data of additive-free hole-only devices. Symbols $x,-, \square$ stand for minimum or maximum, $1 \%$ or $99 \%$ and averaged values, respectively. The bottom and upper sides of the square indicate lower and upper quartiles, respectively.

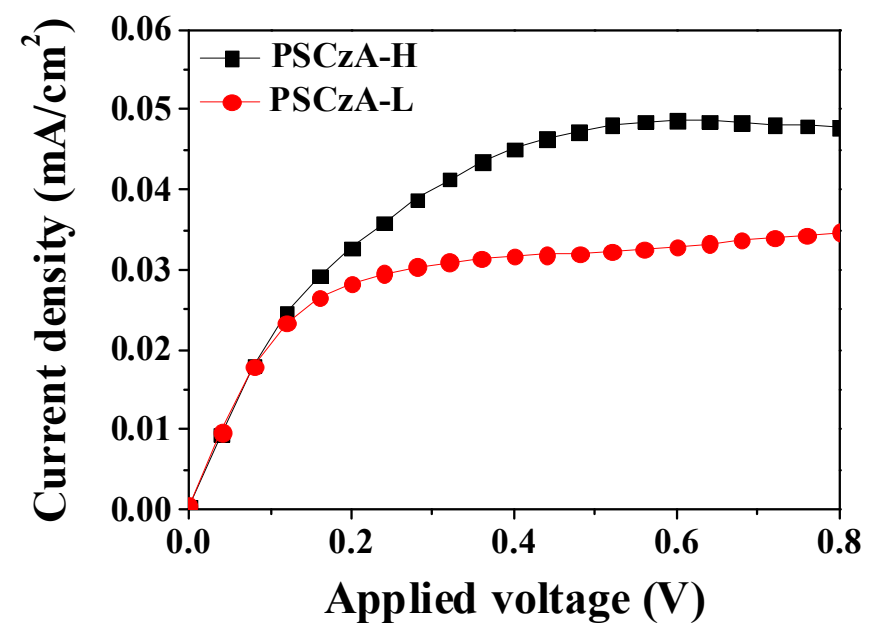

Figure 7. $J-V$ characteristics of the additive-containing hole-only devices.

Electrical conductivity can estimate carrier hopping in the ssHTM because it is proportional to the product of mobility and carrier concentration. EIS measurements of ssDSCs were performed to calculate the electrical conductivity. Figure 8 shows the Nyquist plots of the EIS spectra for the ssDSCs with PBCzA measured at $-0.7 \mathrm{~V}$ in the dark, providing the sheet resistance $\left(\mathrm{R}_{\mathrm{s}}\right)$ and interface resistances. We observed three distinct semicircles corresponding to the resistances for carrier transport at the Pt/HTM $\left(\mathrm{R}_{1}\right)$ and $\mathrm{TiO}_{2} / \mathrm{N} 719 / \mathrm{HTM}\left(\mathrm{R}_{2}\right)$ interfaces and within the HTM $\left(\mathrm{R}_{3}\right)$ in the ssDSCs. The fitted resistances using a Z-view software are given in Table 3 . The conductivity was calculated using $l /\left(A \cdot R_{3}\right)$, where $l$ is the thickness (around $22 \mu \mathrm{m}$ ) of the HTM between the two FTO glasses, $A$ is the photoactive area $\left(0.25 \mathrm{~cm}^{2}\right)$ of ssDSCs, and $R_{3}$ is the fitted resistance determined from the EIS measurements [7]. In the additives' presence, the electrical conductivity in the ssDSC-H's PBCz-H $(15.88 \mathrm{mS} / \mathrm{m})$ was higher than that of the ssDSC-L's PBCz-L $(10.94 \mathrm{mS} / \mathrm{m})$, indicating a rapid band and hopping transport of holes in the PBCz-H. Thus, a higher $J_{s c}$ in the ssDSC-H could be attributed to higher hole mobility and electrical conductivity in the PBCzA-H layer than those in the PBCzA-L layer. 


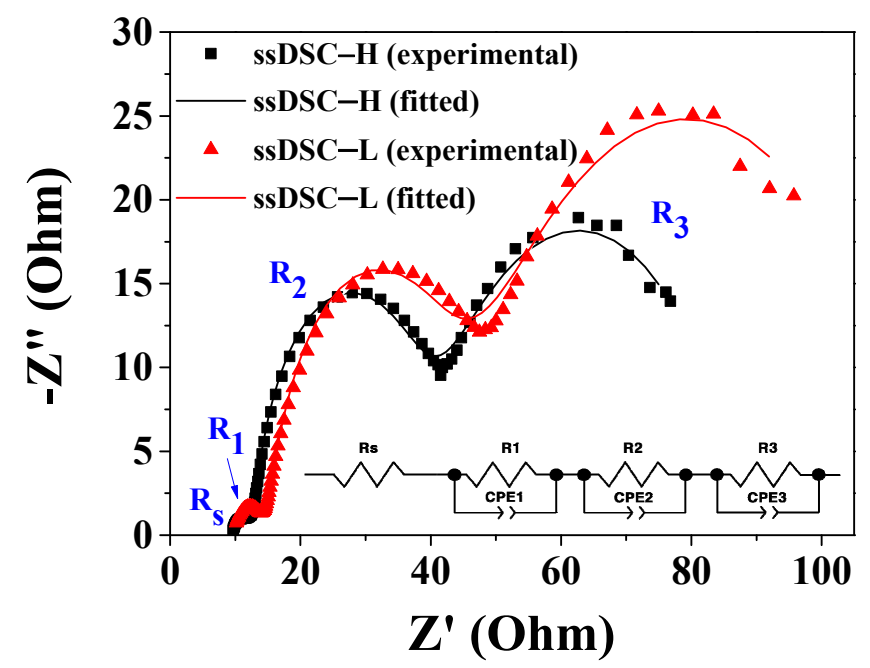

Figure 8. Nyquist plots of EIS spectra for the ssDSCs with PBCzA-H and PBCzA-L, measured at -0.7 V in the dark. Inset shows the equivalent circuit for ssDSC.

Table 3. Fitted EIS values for ssDSCs and electrical conductivity of polymeric hole-transporting material (HTMs).

\begin{tabular}{cccccc}
\hline Devices & $\mathbf{R}_{\mathbf{s}}(\boldsymbol{\Omega})$ & $\mathbf{R}_{\mathbf{1}}(\boldsymbol{\Omega})$ & $\mathbf{R}_{\mathbf{2}}(\boldsymbol{\Omega})$ & $\mathbf{R}_{\mathbf{3}}(\boldsymbol{\Omega})$ & Conductivity $(\mathbf{m S} / \mathbf{m})$ \\
\hline ssDSC-H & 9.85 & 1.65 & 19.64 & 55.41 & 15.88 \\
ssDSC-L & 10.08 & 2.99 & 20.18 & 80.46 & 10.94 \\
\hline
\end{tabular}

\subsection{Effects of the Molecular Weight on $V_{o c}$}

Figure 3 and Table 2 show that the ssDSC-H's $V_{o c}$ value $(0.590 \mathrm{~V})$ was also higher than that of the ssDSC-L $(0.566 \mathrm{~V})$, which accounts for a $13 \%$ contribution to the PCE's improvement. In solar cells based on organic semiconductors, $V_{o c}$ is generally written as Equation (3):

$$
V_{O C}=\frac{n k_{B} T}{q} \ln \left(\frac{J_{S C}}{J_{0}}\right)+\frac{\Delta E_{D A}}{2 q}
$$

where $n$ is the ideality factor, $J_{0}$ is the reverse saturation current density, and $\Delta E_{D A}$ is the activation energy for charge separation at the donor-acceptor interface [29-31].

Equation (3) shows that $V_{o c}$ depends on the charge separation at the donor and acceptor interface $\left(\Delta E_{D A}\right)$. Shu et al. reported that high mobility HTMs can extract holes easily from the donor layer, increasing the $V_{o c}$ [29]. They also investigated the hole mobility effects of various HTMs on the $V_{o c}$ value in organic solar cells with a configuration of ITO/HTM/donor/acceptor/buffer layer/Al and showed that a HTM with the highest mobility produced the largest $V_{o c}(1.15 \mathrm{~V})$, whereas the other HTMs with lower mobility values exhibited a smaller $V_{o c}$ value. They attribute the increase in the $V_{o c}$ to a rapid hole extraction from donor to HTM, leading to effective charge separation $\left(\Delta E_{D A}\right)$ [29]. Elumalai et al. also reported that the $V_{o c}$ in organic solar cells increased linearly with decreasing temperature and then saturated at lower temperatures (around $150 \mathrm{~K}$ ), which was attributed to the temperature-dependent mobility of organic semiconductors [30]. Conjugated polymers are energetically disordered due to conformational variations [32], which can affect $V_{o c}$. Elumalai et al. also found that $V_{o c}$ decreased with increasing disorder, which was attributed to the disorder-induced carrier traps decreasing the carrier mobility [30]. Thus, the $V_{o c}$ value is closely related to the carrier mobility, which affects the charge separation.

As mentioned earlier, the hole mobility of the additive-free hole-only device with PBCzA-H was about $290 \%$ higher than that of the counterpart with PBCzA-L. Moreover, the dark currents of the additive-containing device with PBCzA-H were higher than those of the device with PBCzA-L. 
Accordingly, a higher $V_{o c}$ value in the ssDSC-H was due to an effective charge separation $\left(\Delta E_{D A}\right)$, resulting from the higher hole mobility than in the ssDSC-L.

\subsection{Effects of the Molecular Weight on FF}

The ssDSC-H device with PBCzA-H showed a higher FF value (67.30\%) compared to that of the ssDSC-L device with PBCzA-L (64.05\%), corresponding to the $15 \%$ increase in PCE. The FF, defined as the ratio of the solar cell's maximum power to the product of $V_{o c}$ and $J_{s c}$, is affected by the series $\left(R_{s e}\right)$ and shunt $\left(R_{s h}\right)$ resistances [33-35]. A higher $F F$ value in solar cells can be achieved by a decrease in $R_{s e}$ and/or an elevation in $R_{s h}$ [33]. The $R_{s e}$ and $R_{s h}$ values could be obtained from the slope of the $J-V$ curves at $V_{o c}$ and $J_{s c}$, as shown in Equations (4) and (5), respectively [36].

$$
\begin{aligned}
& R_{s e}=-\left(\frac{d J}{d V}\right)_{O C}{ }^{-1} \\
& R_{s h}=-\left(\frac{d J}{d V}\right)_{S C}{ }^{-1}
\end{aligned}
$$

As presented in Table 2, a lower $R_{s e}$ value $\left(11.0 \Omega \mathrm{cm}^{2}\right)$ in the ssDSC-H with PBCzA-H was recorded compared to that of the ssDSC-L with PBCzA-L $\left(13.3 \Omega \mathrm{cm}^{2}\right)$. Moreover, the $R_{s h}$ of the ssDSC-H increased by $1238.4 \Omega \mathrm{cm}^{2}$ compared to that of the ssDSC-L $\left(1100.1 \Omega \mathrm{cm}^{2}\right)$. The $R_{s e}$ value is closely related to solar cells' internal resistance and can be partially estimated via EIS measurements. As shown in Figure 8 and Table 3, lower resistances at the interface of $\mathrm{TiO}_{2} / \mathrm{N} 719 / \mathrm{HTM}\left(\mathrm{R}_{2}\right)$ and within the HTM $\left(\mathrm{R}_{3}\right)$ were recorded in the ssDSC-H due to PBCzA-H's higher hole mobility, contributing to the decrease in the ssDSC-H's $R_{s e} . R_{s h}$ is influenced by the charge recombination and the leakage current, i.e., the recombination could decrease the $R_{s h}$ value in the organic solar cells [34]. It is already known that the carrier mobility affects the charge extraction and recombination dynamics, i.e., a more balanced carrier mobility could lead to reduced charge recombination and thereby to a higher $F F[28,37,38]$. One study reported that the electron mobility of inorganic semiconductor $\mathrm{TiO}_{2}$ ranged from 0.1 to $4 \mathrm{~cm}^{2} / \mathrm{Vs}$, which is much higher than the organic HTMs' hole mobility [39]. In this study, hole mobility measurements showed higher hole mobility in PBCzA-H. These results suggest a more balanced electron and hole mobility in the ssDSC-H than in the ssDSC-L, reducing the charge recombination and increasing the $R_{s h}$ value in the ssDSC-H. Thus, it can be concluded that the increased FF value was attributed to the lowered $R_{s e}$ and the elevated $R_{s h}$ by the increase of hole mobility in PBCz-H.

\section{Conclusions}

Polymeric HTMs with both biscarbazole and aniline moieties in the repeating unit were synthesized, and the molecular weight effects on the photovoltaic performance of ssDSCs were investigated. When the lower-molecular-weight PBCzA-L $(2450 \mathrm{~g} / \mathrm{mol})$ was applied as a hole-transporting layer together with additives, the ssDSCs showed a photovoltaic performance of $6.60 \pm 0.63 \mathrm{~mA} / \mathrm{cm}^{2}$ of $J_{s c}, 0.559 \pm 0.006 \mathrm{~V}$ of $V_{o c}$, and $68.18 \pm 2.67 \%$ of $F F$, which led to a PCE of $2.51 \pm 0.17 \%$. In contrast, in the device with the higher-molecular-weight PBCzA-H $(21,200 \mathrm{~g} / \mathrm{mol})$, the PCE was increased to $3.15 \pm 0.43 \%\left(J_{s c}=7.86 \pm 1.10 \mathrm{~mA} / \mathrm{cm}^{2}, V_{o c}=0.585 \pm 0.013 \mathrm{~V}\right.$, and $\left.F F=68.58 \pm 3.51 \%\right)$. The enhanced performance was attributed to higher hole mobility and electrical conductivity of PBCzA-H than those of PBCzA-L. Notably, the ssDSC-H showed the highest PCE of 3.79\% even though the thickness of the hole-transporting layer (composed of polymeric PBCzA-H and additives) was over $7 \mu \mathrm{m}$. This result indicates that a higher-molecular-weight polymeric HTM is a better choice to obtain superior photovoltaic performance in ssDSCs. 
Supplementary Materials: The following are available online at http://www.mdpi.com/2079-4991/10/12/2516/s1, Scheme S1. Synthetic route to bis[6-bromo-N-(2-ethylhexyl)-carbazole-3-yl], Figure S1: ${ }^{1} \mathrm{H}$ NMR spectrum of N-(2-ethylhexyl)-carbazole, Figure S2: ${ }^{13} \mathrm{C}$ NMR spectrum of N-(2-ethylhexyl)-carbazole, Figure S3: ${ }^{1} \mathrm{H}$ NMR spectrum of bis[N-(2-ethylhexyl)-carbazole-3-yl], Figure S4: ${ }^{13} \mathrm{C}$ NMR spectrum of bis[N-(2-ethylhexyl)-carbazole-3-yl], Figure S5: ${ }^{1} \mathrm{H}$ NMR spectrum of bis[6-bromo-N-(2-ethylhexyl)-carbazole-3-yl], Figure S6: ${ }^{13} \mathrm{C}$ NMR spectrum of bis[6-bromo-N-(2-ethylhexyl)-carbazole-3-yl], Scheme S2. Polymerization route to PBCzA, Figure S7: GPC elution profiles for PBCzA-H and PBCzA-L, Figure S8: Absorption and emission spectra of PBCzA in (a) solutions and (b) films, Figure S9: Photoelectron spectroscopy analysis of PBCzA-H and PBCzA-L in a thin film, Table S1: Averages and standard deviations of cell performance, which were measured using four cells with PBCzA layers. Figure S10: Cross-sectional SEM image (a) and EDS mapping images showing the distribution of carbon (b), nitrogen (c), titanium (d), and oxygen (e) in a decapped ssDSC with PBCzA-H (without additives). Figure S11: Cross-sectional SEM image (a) and EDS mapping images showing the distribution of carbon (b), nitrogen (c), titanium (d), and oxygen (e) in a decapped ssDSC with PBCzA-L (without additives). Table S2. Averages and standard deviations of hole mobilities, which were measured using six additive-free hole-only devices.

Author Contributions: Conceptualization, Y.K. and Y.S.H.; methodology, M.K., K.S.K., N.V.N., Y.L., and Y.S.J.; formal analysis, M.K., K.S.K., N.V.N., Y.L., and Y.S.J.; writing-original draft preparation, Y.K and Y.S.H.; writing-review and editing, Y.C.; funding acquisition, Y.K., Y.S.H., and Y.C. All authors have read and agreed to the published version of the manuscript.

Funding: This work was supported by the National Research Foundation of Korea (NRF) grant funded by the Korean government (MSIT) (No. NRF-2019R1F1A1058801). This work was also supported by the Human Resources Program in Energy Technology of the Korea Institute of Energy Technology Evaluation and Planning (KETEP) and granted financial resources from the Ministry of Trade, Industry and Energy, the Republic of Korea (No. 20194010201760).

Conflicts of Interest: The authors declare no conflict of interest. The funders had no role in the design of the study; in the collection, analyses, or interpretation of data; in the writing of the manuscript, or in the decision to publish the results.

\section{References}

1. Gong, J.; Sumathy, K.; Qiao, Q.; Zhou, Z. Review on dye-sensitized solar cells (DSSCs): Advanced techniques and research trends. Renew. Sust. Energ. Rev. 2017, 68, 234-236. [CrossRef]

2. Sharma, K.; Sharma, V.; Sharma, S.S. Dye-sensitized solar cells: Fundamentals and current status. Nanoscale Res. Lett. 2018, 13, 381. [CrossRef] [PubMed]

3. Benesperi, I.; Michaels, H.; Freitang, M. The researcher's guide to solid-state dye-sensitized solar cells. J. Mater. Chem. C. 2018, 6, 11903-11942. [CrossRef]

4. Koh, J.K.; Kim, J.; Kim, B.; Kim, J.H.; Kim, E. Highly efficient, iodine-free dye-sensitized solar cells with solid-state synthesis of conducting polymers. Adv. Mater. 2011, 23, 1641-1646. [CrossRef] [PubMed]

5. Chung, I.; Lee, B.; He, J.; Chang, R.P.H.; Kanatzidis, M.G. All-solid-state dye-sensitized solar cells with high efficiency. Nature 2012, 485, 486-489. [CrossRef]

6. Lee, B.; Stoumpos, C.C.; Zhou, N.; Hao, F.; Malliakas, C.; Yeh, C.-Y.; Marks, T.J.; Kanatazidis, M.G.; Chang, R.P.H. Air-stable molecular semiconducting iodosalts for solar cell applications: $\mathrm{Cs}_{2} \mathrm{SnI}_{6}$ as a hole conductor. J. Am. Chem. Soc. 2014, 136, 15379-15385. [CrossRef]

7. Cao, Y.; Saygili, Y.; Ummadisingu, A.; Teuscher, J.; Luo, J.; Pellet, N.; Giordano, F.; Zakeeruddin, S.M.; Moser, J.-E.; Freitan, M.; et al. 11\% efficiency solid-state dye-sensitized solar cells with copper(II/I) hole transport materials. Nat. Commun. 2016, 8, 15390. [CrossRef]

8. Freitag, M.; Daniel, Q.; Pazoki, M.; Sveinbjörnsson, K.; Zhang, J.; Sun, L.; Hagfeldt, A.; Boschloo, G. High-efficiency dye-sensitized solar cells with molecular copper phenanthroline as solid hole conductor. Energy Environ. Sci. 2015, 8, 2634-2637. [CrossRef]

9. Kashif, M.K.; Milhuisen, R.A.; Nippe, M.; Hellerstedt, J.; Zee, D.Z.; Duffy, N.W.; Halstead, B.; Angelis, F.D.; Fantacci, S.; Fuhrer, M.S.; et al. Cobalt polypyridyl complexes as transparent solution-processable solid-state charge transport materials. Adv. Energy Mater. 2016, 6, 1600874. [CrossRef]

10. Yang, X.; Wang, H.; Cai, B.; Yu, Z.; Sun, L. Progress in hole-transporting materials for perovskite solar cells. J. Energy Chem. 2018, 27, 650-672. [CrossRef]

11. Krishna, A.; Grimsdale, A.C. Hole transporting materials for mesoscopic perovskite solar cells-Towards a rational design? J. Mater. Chem. A. 2017, 5, 16446-16466. [CrossRef]

12. Lee, C.W.; Kim, O.Y.; Lee, J.Y. Organic materials for organic electronic devices. J. Ind. Eng. Chem. 2014, 20, 1198-1208. [CrossRef] 
13. Xu, B.; Sheibani, E.; Liu, P.; Zhang, J.; Tian, H.; Vlachopoulos, N.; Boschloo, G.; Kloo, L.; Hagfeldt, A.; Sun, L. Carbazole-based hole-transport materials for efficient solid-state dye-sensitized solar cells and perovskite solar cells. Adv. Mater. 2014, 26, 6629-6634. [CrossRef]

14. Thaengthong, A.-M.; Saengsuwan, S.; Jungsuttiwong, S.; Keawin, T.; Sudyoadsuk, T.; Promarak, V. Synthesis and characterization of high $T_{\mathrm{g}}$ carbazole-based amorphous hole-transporting materials for organic light-emitting devices. Tetrahedron Lett. 2011, 52, 4749-4752. [CrossRef]

15. Bieliauskas, A.; Getautis, V.; Martynaitis, V.; Jankauskas, V.; Kamarauskas, E.; Krikštolaitytè, S.; Šačkus, A. Synthesis of electroactive hydrazones derived from carbazolyl-based 2-propenals for optoelectronics. Synth. Met. 2013, 179, 27-33. [CrossRef]

16. Wang, H.; Ryu, J.-T.; Kwon, Y. Carbazole/triarylamine based polymers as a hole injection/transport layer in organic light emitting devices. J. Nanosci. Nanotechnol. 2012, 12, 4330-4334. [CrossRef]

17. Wang, H.; Ryu, J.T.; Han, Y.S.; Kim, D.H.; Choi, B.D.; Park, L.S.; Kwon, Y. Alternating copolymers of $\mathrm{N}$-(2-ethylhexyl)-carbazole derivatives with aniline units: Synthesis and properties. Mol. Cryst. Liq. Cryst. 2006, 459, 85-365. [CrossRef]

18. Baek, G.W.; Kim, Y.-J.; Jung, K.-H.; Han, Y.S. Enhancement of solar cell performance through the formation of a surface dipole on polyacrylonitrile-treated $\mathrm{TiO}_{2}$ photoelectrodes. J. Ind. Eng. Chem. 2019, 73, 260-267. [CrossRef]

19. Kim, J.Y.; Kwak, G.; Choi, Y.C.; Kim, D.-H.; Han, Y.S. Enhanced performance of perovskite solar cells by incorporation of a triphenylamine derivative into hole-transporting poly(3-hexylthiophene) layers. J. Ind. Eng. Chem. 2019, 73, 175-181. [CrossRef]

20. Cinà, L.; Taheri, B.; Reale, A.; Di Carlo, A. Diffusion length mapping for dye-sensitized solar cells. Energies 2016, 9, 686. [CrossRef]

21. Lamberti, A.; Sacco, A.; Bianco, S.; Manfredi, D.; Armandi, M.; Quaglio, M.; Tresso, E.; Pirri, C.F. An easy approach for the fabrication of $\mathrm{TiO}_{2}$ nanotube-based transparent photoanodes for dye-sensitized solar cells. Sol. Energy. 2019, 95, 90-98. [CrossRef]

22. Longeaud, C.; Allah, A.F.; Schmidt, J.; El Yaakoubi, M.; Berson, S.; Lemaitre, N. Determination of diffusion lengths in organic semiconductors: Correlation with solar cell performances. Org. Electron. 2016, 31, $253-257$. [CrossRef]

23. Xing, G.; Mathews, N.; Sun, S.; Lim, S.S.; Lam, Y.M.; Grätzel, M.; Mhaisalkar, S.; Sum, T.C. Long-range balanced electron- and hole-transport lengths in organic-inorganic $\mathrm{CH}_{3} \mathrm{NH}_{3} \mathrm{PbI}_{3}$. Science 2013, 342, 344-347. [CrossRef] [PubMed]

24. Mikhnenko, O.V.; Blom, P.W.M.; Nguyen, T.-Q. Exciton diffusion in organic semiconductors. Energy Environ. Sci. 2015, 8, 1867-1888. [CrossRef]

25. Peng, J.; Chen, Y.; Zheng, K.; Pullerits, T.; Liang, Z. Insights into charge carrier dynamics in organo-metal halide perovskites: From neat films to solar cells. Chem. Soc. Rev. 2017, 46, 5714-5729. [CrossRef]

26. Seo, J.-Y.; Kim, H.-S.; Akin, S.; Stojanovic, M.; Simon, E.; Fleischer, M.; Hagfeldt, A.; Zakeeruddin, S.M.; Grätzel, M. Novel p-dopant toward highly efficient and stable perovskite solar cells. Energy Environ. Sci. 2018, 11, 2985-2992. [CrossRef]

27. Kim, G.-W.; Kang, G.; Byranvand, M.M.; Lee, G.-Y.; Park, T. Gradated mixed hole transport layer in a perovskite solar cell: Improving moisture stability and efficiency. ACS Appl. Mater. Interfaces 2017, 9, 27720-27726. [CrossRef]

28. Nia, N.Y.; Matteocci, F.; Cina, L.; Carlo, A.D. High-efficiency perovskite solar cell based on poly(3-hexylthiophene): Influence of molecular weight and mesoscopic scaffold layer. ChemSusChem 2017, 10, 3854-3860. [CrossRef]

29. Kulshreshtha, C.; Choi, J.W.; Kim, J.-K.; Jeon, W.S.; Suh, M.C.; Park, Y.; Kwon, J.H. Open-circuit voltage dependency on hole-extraction layers in planar heterojunction organic solar cells. Appl. Phys. Lett. 2011, 99, 023308. [CrossRef]

30. Elumalai, N.K.; Uddin, A. Open circuit voltage of organic solar cells: An in-depth review. Energy Environ. Sci. 2016, 9, 391-410. [CrossRef]

31. Perez, M.D.; Borek, C.; Forrest, S.R.; Thompson, M.E. Molecular and morphological influences on the open circuit voltages of organic photovoltaic devices. J. Am. Chem. Soc. 2009, 131, 9281-9286. [CrossRef] [PubMed] 
32. Hood, S.; Zarrabi, N.; Meredith, P.; Kassal, I.; Armin, A. Measuring energetic disorder in organic semiconductors using the photogenerated charge-separation efficiency. J. Phys. Chem. Lett. 2019, 10, 3863-3870. [CrossRef] [PubMed]

33. Wang, F.; Shimazaki, A.; Yang, F.; Kanahashi, K.; Matsuki, K.; Miyauchi, Y.; Takenobu, T.; Wakamiya, A.; Murata, Y.; Matsuda, K. Highly efficient and stable perovskite solar cells by interfacial engineering using solution-processed polymer layer. J. Phys. Chem. C. 2017, 121, 1562-1568. [CrossRef]

34. Tvingstedt, K.; Gil-Escrig, L.; Momblona, C.; Rieder, P.; Kiermasch, D.; Sessolo, M.; Baumann, A.; Bolink, H.J.; Dyakonov, V. Removing leakage and surface recombination in planar perovskite solar cells. ACS Energy Lett. 2017, 2, 424-430. [CrossRef]

35. Min, J.; Zhang, Z.-G.; Hou, Y.; Quiroz, C.O.R.; Przybilla, T.; Bronnbauer, C.; Guo, F.; Forberich, K.; Azimi, H.; Ameri, T.; et al. Interface engineering of perovskite hybrid solar cells with solution-processed perylene-diimide heterojunctions toward high performance. Chem. Mater. 2015, 27, 227-234. [CrossRef]

36. Auf der Maur, M.; Di Carlo, A. Analytic approximations for solar cell open circuit voltage, short circuit current and fill factor. Sol. Energy. 2019, 187, 358-367. [CrossRef]

37. Ebenhoch, B.; Thomson, S.A.J.; Genevičius, K.; Juška, G.; Samuel, I.D.W. Charge carrier mobility of the organic photovoltaic materials $\mathrm{PTB} 7$ and $\mathrm{PC}_{71} \mathrm{BM}$ and its influence on device performance. Org. Electron. 2015, 22, 62-68. [CrossRef]

38. Yan, J.; Luo, G.; Xiao, B.; Wu, H.; He, Z.; Cao, Y. Origin of high fill factor in polymer solar cells from semiconducting polymer with moderate charge carrier mobility. Org. Electron. 2015, 24, 125-130. [CrossRef]

39. Chandiran, A.K.; Abdi-Jalebi, M.; Nazeeruddin, M.K.; Grätzel, M. Analysis of electron transfer properties of $\mathrm{ZnO}$ and $\mathrm{TiO}_{2}$ photoanodes for dye-sensitized solar cells. ACS Nano. 2014, 8, 2261-2268. [CrossRef]

Publisher's Note: MDPI stays neutral with regard to jurisdictional claims in published maps and institutional affiliations. 